\title{
DDE Design Status Report Nov 2011
}

\author{
N.E. Woolstenhulme \\ R.B. Nielson
}

November 2011

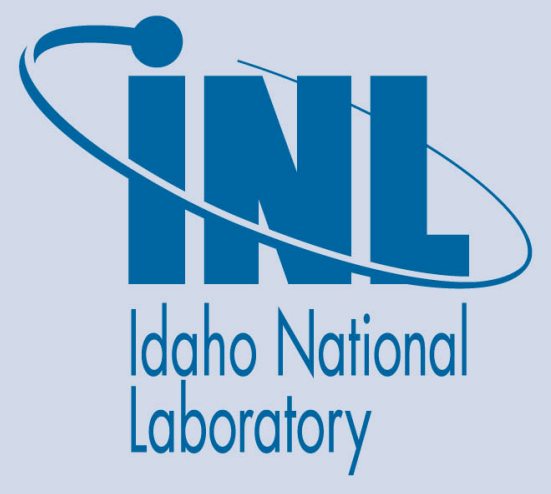

The INL is a U.S. Department of Energy National Laboratory operated by Battelle Energy Alliance 
INL/EXT-11-23991

\section{DDE Design Status Report Nov 2011}

N. E. Woolstenhulme

R. B. Nielson

November 2011

\section{Idaho National Laboratory \\ Idaho Falls, Idaho 83415}

http://www.inl.gov

\section{Prepared for the}

U.S. Department of Energy

Office of National Nuclear Security Administration

Under DOE Idaho Operations Office

Contract DE-AC07-05ID14517 


\section{DISCLAIMER}

This information was prepared as an account of work sponsored by an agency of the U.S. Government. Neither the U.S. Government nor any agency thereof, nor any of their employees, makes any warranty, expressed or implied, or assumes any legal liability or responsibility for the accuracy, completeness, or usefulness, of any information, apparatus, product, or process disclosed, or represents that its use would not infringe privately owned rights. References herein to any specific commercial product, process, or service by trade name, trade mark, manufacturer, or otherwise, does not necessarily constitute or imply its endorsement, recommendation, or favoring by the U.S. Government or any agency thereof. The views and opinions of authors expressed herein do not necessarily state or reflect those of the U.S. Government or any agency thereof. 


\title{
DDE Design Status Report Nov 2011
}

\author{
INL/EXT-11-23991
}

November 2011

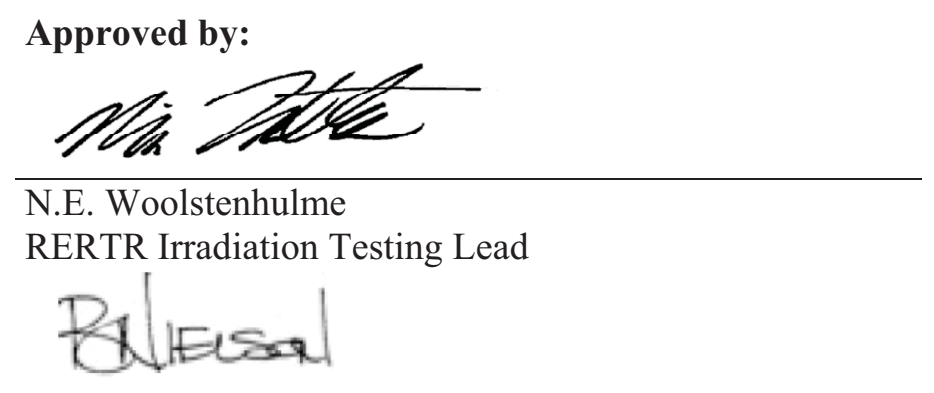

R.B. Nielson

DDE Experiment Manager

11-30-11

$11-30-11$

Date

Date 


\section{EXECUTIVE SUMMARY}

The GTRI-Convert Fuel Development pillar is currently focused on qualification of the base monolithic fuel to enable Low Enriched Uranium (LEU) conversions of the Massachusetts Institutes of Technology Reactor (MITR), University of Missouri Research Reactor (MURR), and National Bureau of Standards Reactor (NBSR). Each of these reactors requires a unique fuel element geometry and configuration of the base monolithic fuel to enable conversion. The licensing basis of these reactors restricts them from testing lead test elements of their respective LEU fuel element designs. Consequently, irradiation of Design Demonstration Experiments (DDE) in other reactors is needed to confirm performance under stringent prototypic parameters, to show resistance to worrisome failure modes, to demonstrate fabrication by producing the plates/elements as demonstration products, and to give confidence in the LEU fuel designs prior to conversion.

DDE-MITR is proposed to be irradiated in the Advanced Test Reactor (ATR) in medium "I" positions. This allows for position "shuffling" to simulate MITR power evolutions, axial asymmetry to simulate MITR fission gradients, and can accommodate four full-size MITR fuel plates at target experiment conditions if the fuel meat is enriched to about $40 \%$. The low irradiation user costs, high availability, and high ATR operation time per year ( 215 days per year) associated with med "I" irradiations also make them make them well suited for DDE-MITR. This experiment assembly is intended to be examined during outages with the ATR in-canal channel gap probe.

DDE-MURR is proposed to be irradiated in the Belgian Reactor 2 (BR2) primarily because this is the only realistic option which can accommodate the entire MURR element geometry and reach target irradiation conditions. DDE-MURR is the most desirable to be a full-size element since it contains 24 distinct plate geometries (MITR and NBSR both employ an array of only one plate geometry each). Recent experience with BR2 has shown excellent performance in quality of work, contracting, and timeliness. BR2 personnel have indicated that a full size DDE-MURR element could be accommodated in the core and achieve target irradiation conditions. This can be accomplished with $19.75 \%$ enriched fuel meat. This path will likely require that BR2 be provided with an in-canal channel gap probe.

DDE-NBSR is proposed to be irradiated in the ATR in the Center Flux Trap (CFT) position. Removal of the Loop 2A facility will be required to utilize the full geometry of the CFT. The CFT is needed to achieve the target irradiation conditions which can be accomplished with nine full size NBSR plates at about 35\% fuel meat enrichment. While BR2 personnel have indicated capability of irradiating DDENBSR concurrent to DDE-MURR, this path is not recommended as NBSR's high fission density target, combined with BR2 low operating time per year, would give way to considerable schedule delays. This experiment assembly would also be purposed for examination with the ATR in-canal channel gap probe.

While the above recommended paths are not projected to support the currently published conversion schedules, they are the most expeditious options available which accomplish the core DDE objectives. Acceleration of the DDE schedules would likely come at the expense of the experiment objectives. 


\section{CONTENTS}

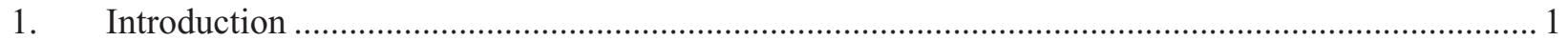

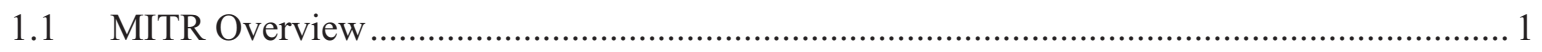

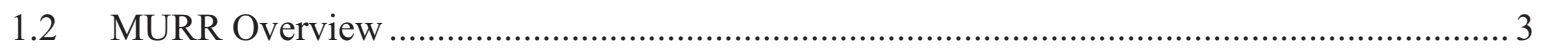

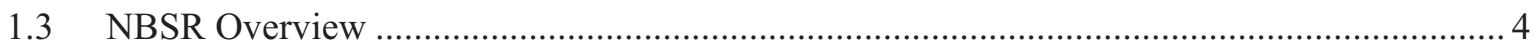

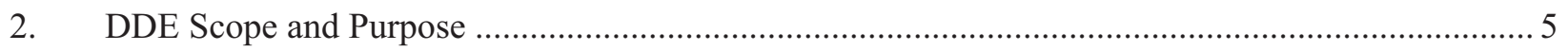

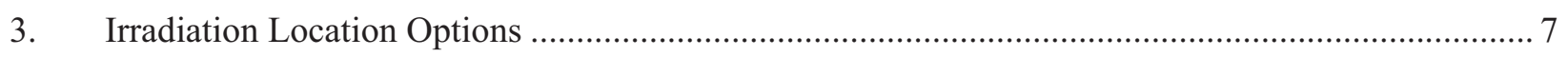

4. DDE Recommended Irradiation Location and Preliminary Designs............................................ 8

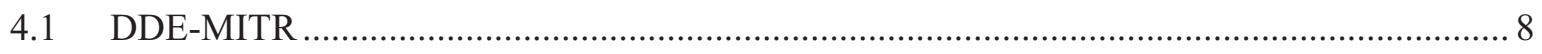

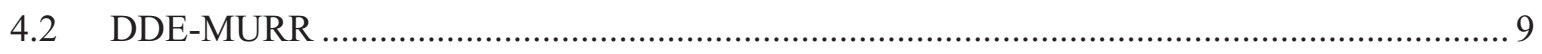

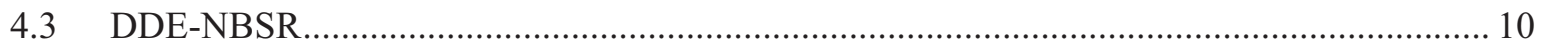

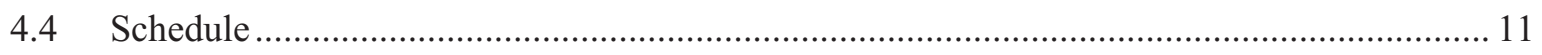

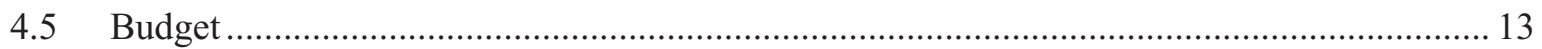

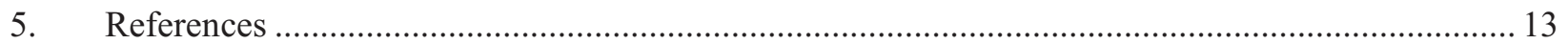




\section{DDE Design Status Report 1}

\section{Introduction}

The National Nuclear Security Agency Global Threat Reduction Initiative employs the Reduced Enrichment for Research and Test Reactors (RERTR) Fuel Development program to facilitate maturation of Low Enriched Uranium (LEU) fuel technology in order to enable conversion of High Power Research Reactors (HPRR) to LEU fuels. The RERTR Fuel Development program has overseen design, fabrication, irradiation, and examination of numerous tests on small to medium sized specimens containing these fuels. To enable the three nearest term HPRR conversions, including the Massachusetts Institutes of Technology Reactor (MITR), University of Missouri Research Reactor (MURR), and National Bureau of Standard Reactor (NBSR), the FD pillar is currently focused on qualification of the "Base Monolithic Design". The Base Monolithic Design consists of uranium-10 wt $\%$ molybdenum alloy (U-10Mo) in the form of a monolithic foil, with thin zirconium interlayers, clad in aluminum by hot isostatic press as seen in Figure 1. ${ }^{[1][2][3]}$

The licensing basis of the three aforementioned HPRR's restricts them from testing lead test elements of their respective LEU fuel element designs. In order to provide the equivalent of a lead test assembly, one Design Demonstration Experiment (DDE) is planned for each of the three NRC licensed reactors. ${ }^{[4]}$

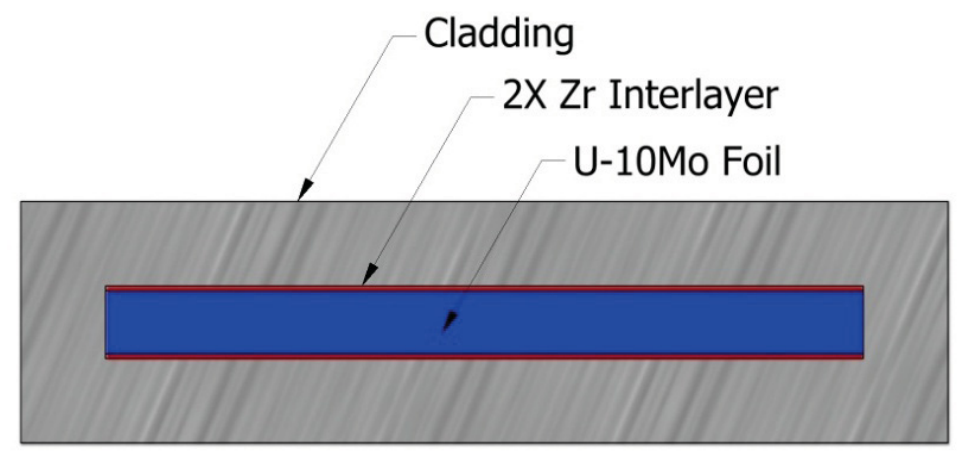

Figure 1: Base Monolithic Design

\section{$1.1 \quad$ MITR Overview}

The Massachusetts Institutes of Technology Reactor based in Cambridge, Massachusetts, is a research reactor designed primarily for experiments and irradiation services using in-core irradiation facilities and various neutron beam ports. The MITR-II core consists of 27 fuel elements positions, of which 24 are typically occupied with fuel elements, in a hexagonal arrangement as seen in Figure 2. The LEU fuel element design consists of an array of 18 fuel plates between side plates in rhombus geometry as seen in Figure 3. Each fuel plate has heat transfer fins on the cladding surfaces. ${ }^{[5][6]}$

MITR and target DDE parameters can be seen in Table 1. 


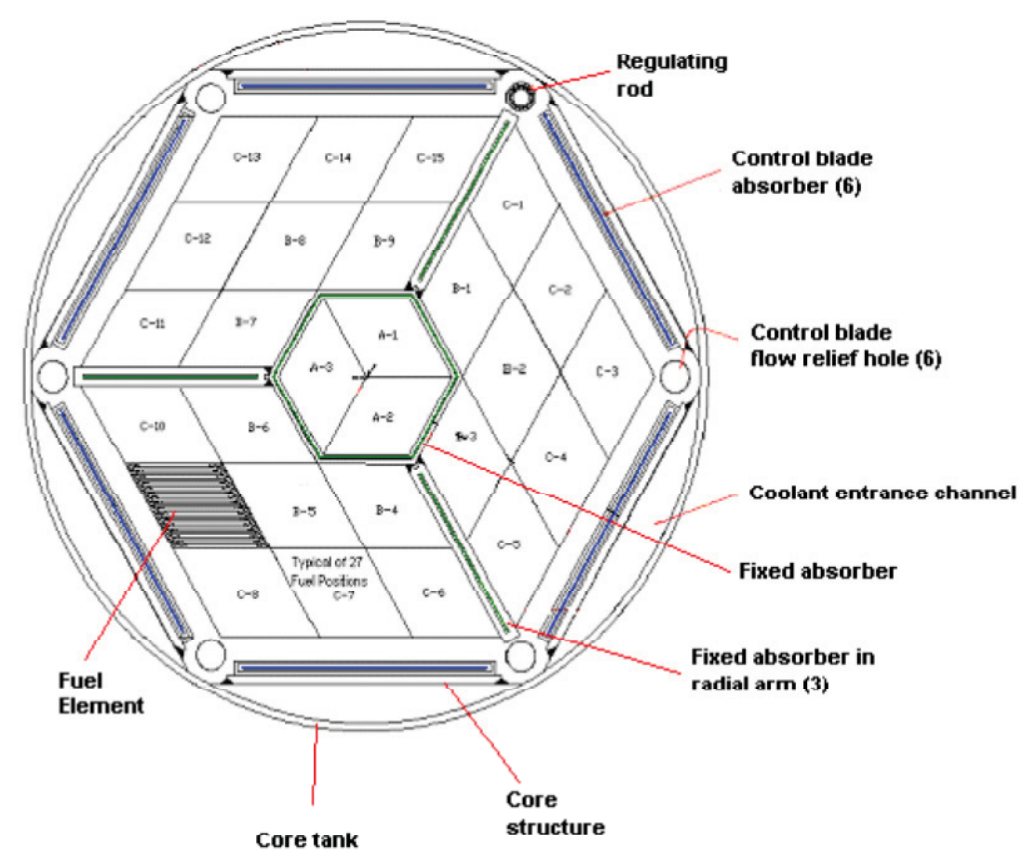

Figure 2: MITR-II Core Layout (reference [6])

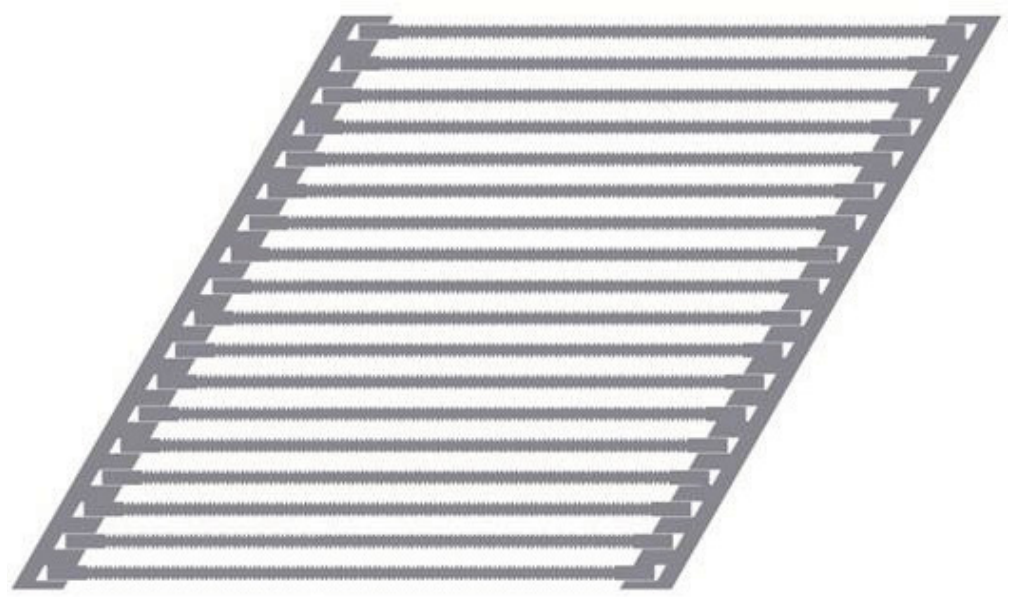

Figure 3: LEU MITR Fuel Element Design

Table 1: MITR Operating Conditions and Reactor Parameters

\begin{tabular}{|c|c|c|}
\hline Parameter & LEU Core Nominal & DDE Target \\
\hline Coolant Velocity $(\mathrm{m} / \mathrm{s})^{[7]}$ & 2.6 & 2.6 \\
\hline Peak Local Heat Flux $\left(\mathrm{W} / \mathrm{cm}^{2}\right)^{[9]}$ & $77^{*}$ & $>77^{*}$ \\
\hline Peak Plate Surface Temp $\left({ }^{\circ} \mathrm{C}\right)^{[10]}$ & 92 & $\sim 92$ \\
\hline Peak Fuel Meat Centerline Temp $\left({ }^{\circ} \mathrm{C}\right)^{[10]}$ & 108 & $2.7 \mathrm{E}+21^{\dagger}$ \\
\hline Peak Fission Density (fissions/cc) & {$[11]$} & $\begin{array}{c}\text { May be limited by oxide } \\
\text { growth }\end{array}$ \\
\hline
\end{tabular}

*Heat flux at surface of fuel meat, not at the finned cladding surface

${ }^{\dagger}$ Peak fission density target may be as high as $3.7 \mathrm{E}+21$ fission/cc ${ }^{[12]}$ 


\subsection{MURR Overview}

The MURR is a multi-disciplinary research and education facility providing a broad range of analytical and irradiation services. The reactor is a pressurized, light-water moderated and cooled. The reactor core assembly is located eccentrically within a cylindrically-shaped, aluminum-lined pool as seen in Figure 4. The fuel region has a fixed geometry consisting of eight fuel elements having identical physical dimensions placed vertically around an annulus in between two cylindrical aluminum reactor pressure vessels. Each fuel assembly is comprised of 24 circumferential plates as seen in Figure 5. ${ }^{[13]}$

MURR and target DDE parameters can be seen in Table 2.

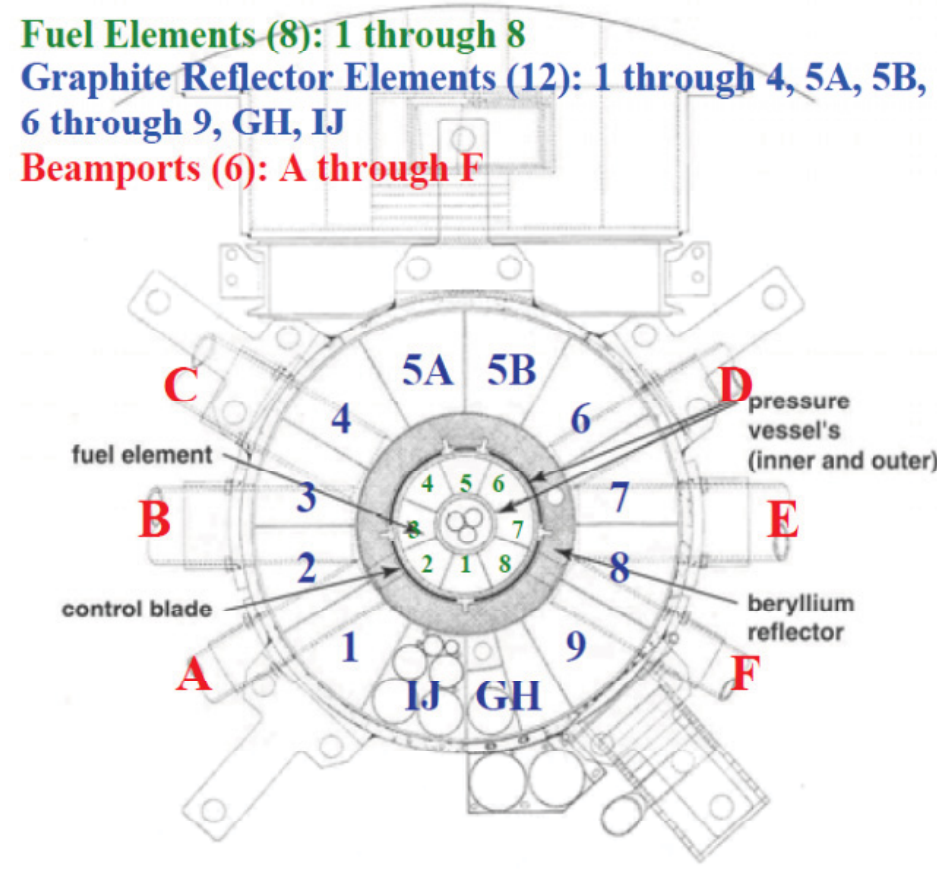

Figure 4: MURR Horizontal Cross Section (reference [13])

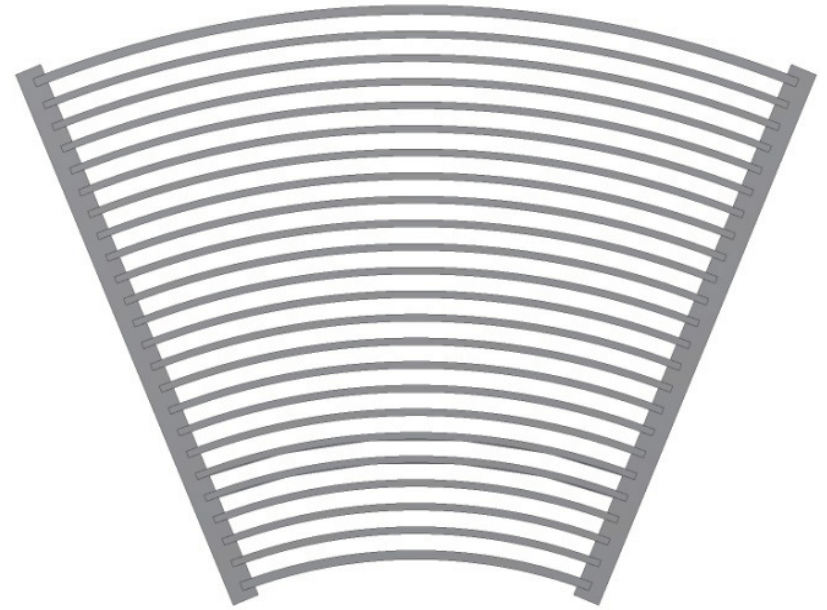

Figure 5: MURR Fuel Element 
Table 2: MURR Operating Conditions and Reactor Parameters

\begin{tabular}{|c|c|c|}
\hline Parameter & LEU Core Nominal & DDE Target \\
\hline Coolant Velocity $(\mathrm{m} / \mathrm{s})^{[14]}$ & 6.6 & 6.6 \\
\hline Peak Local Heat Flux $\left(\mathrm{W} / \mathrm{cm}^{2}\right)^{[16]}$ & 184 & $>184$ \\
\hline Peak Plate Surface Temp $\left({ }^{\circ} \mathrm{C}\right)^{[16]}$ & 114 & $\sim 114$ \\
\hline Peak Fuel Meat Centerline Temp $\left({ }^{\circ} \mathrm{C}\right)^{[16]}$ & 140 & $\sim 140$ \\
\hline Peak Fission Density (fissions/cc) ${ }^{[18]}$ & $4.0 \mathrm{E}+21$ & $>4.0 \mathrm{E}+21$ \\
\hline
\end{tabular}

\section{$1.3 \quad$ NBSR Overview}

The NBSR is cooled and moderated with $\mathrm{D}_{2} \mathrm{O}$ and the fuel elements are placed in a "loose" configuration, i.e. with significant space between each fuel element, in order to achieve design objectives. Each fuel element has a 7-inch gap at the mid-core. This arrangement allows for the beam tubes to point directly to the gap (and not to fuel) in the core as seen in Figure 6. Each fuel element is constructed of 17 plates in each upper and lower half (34 plates per fuel element) in a curved plate geometry as seen in Figure $7 .^{[17]}$

NBSR and target DDE parameters can be seen in Table 3.

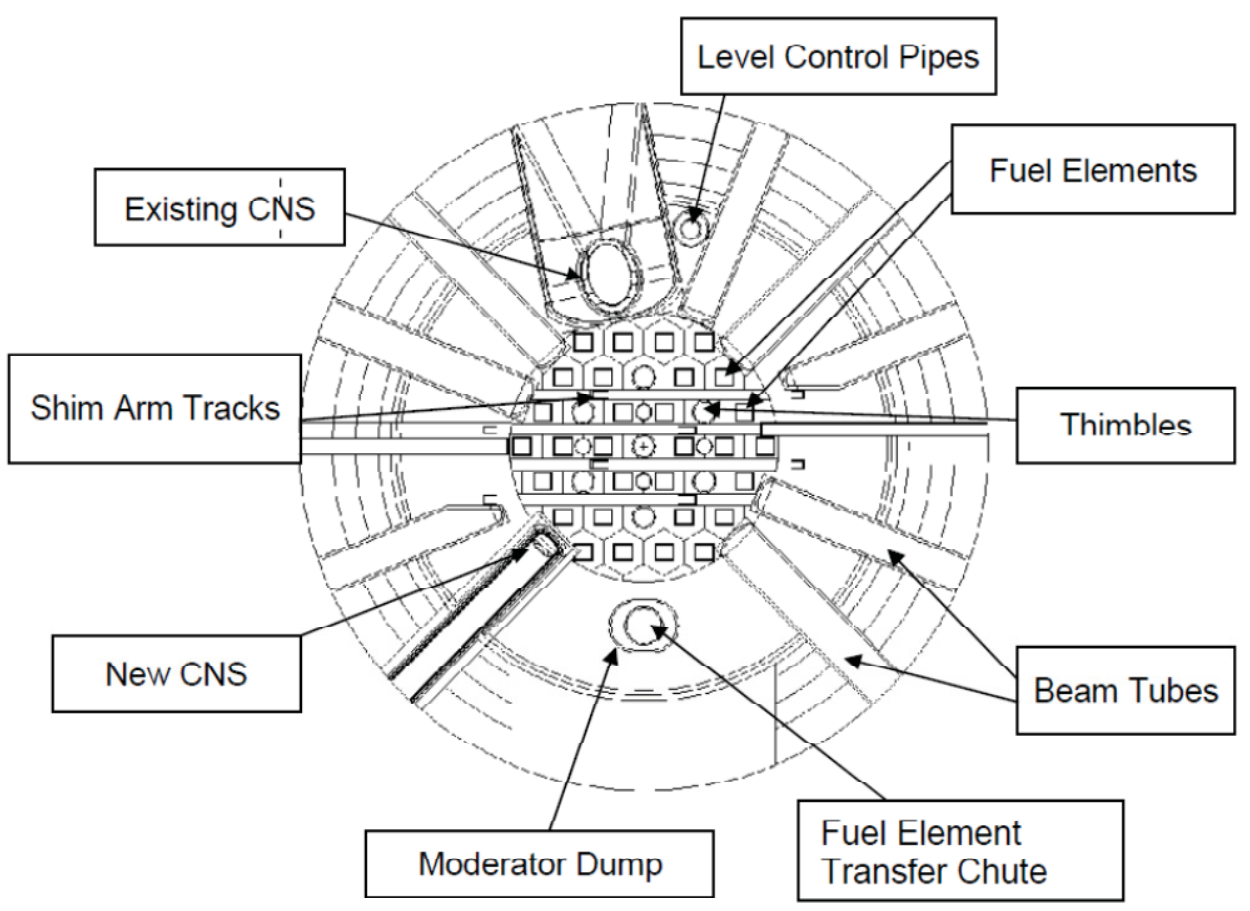

Figure 6: NBSR Core (reference [17]) 


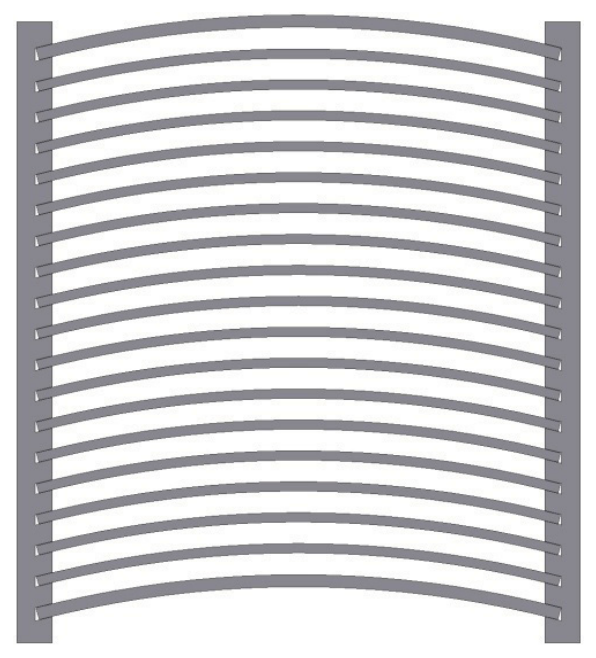

Figure 7: NBSR Fuel Element

Table 3: NBSR Operating Conditions and Reactor Parameters

\begin{tabular}{|c|c|c|}
\hline Parameter & LEU Core Nominal & DDE Target \\
\hline Coolant Velocity $(\mathrm{m} / \mathrm{s})^{[8]}$ & 3.0 & 3.0 \\
\hline Peak Local Heat Flux $\left(\mathrm{W} / \mathrm{cm}^{2}\right)^{[19]}$ & 139 & $>139$ \\
\hline Peak Plate Surface Temp $\left({ }^{\circ} \mathrm{C}\right)^{[19]}$ & 103 & $\sim 103$ \\
\hline Peak Fuel Meat Centerline Temp $\left({ }^{\circ} \mathrm{C}\right)^{[19]}$ & 113 & $\sim 113$ \\
\hline Peak Fission Density (fissions/cc) & $7.75 \mathrm{E}+21^{*}$ & $>7.75 \mathrm{E}+21^{*}$ \\
\hline
\end{tabular}

* Peak fission density is consistent with Full LEU burn-up

\section{DDE Scope and Purpose}

The fuel development irradiation testing program follows the methodology set forth in the technology life cycle $^{[20]}$. This general methodology is paraphrased from reference [21] below:

- Basic Research is conducted first to acquire and disseminate new knowledge.

- Applied Research follows Basic Research and is intended to solve a specific problem, select the best approach, and prove out principles with explicit objectives.

- Development Work follows Applied Research with end use application in a design environment.

Basic Research irradiation testing efforts have been completed for the Base Monolithic Design. Basic Research irradiation tests employed small scale samples of various designs. Increasingly rigorous test conditions were employed to bring out the best designs. The most promising designs were selected for use in Applied Research campaigns. Currently, Applied Research efforts are nearing completion for the Base Monolithic Design. These efforts are characterized by testing of larger samples and/or intense irradiation conditions which are similar to that of HPPR fuel plates. The RERTR Fuel Development program is now becoming increasingly more focused on Development Work campaigns. These will demonstrate the Base Monolithic Design in end-use configurations by irradiating prototypic fuel elements under conditions which mirror the reactor environments for which they are intended. This is represented in Figure 8. ${ }^{[1]}$ 


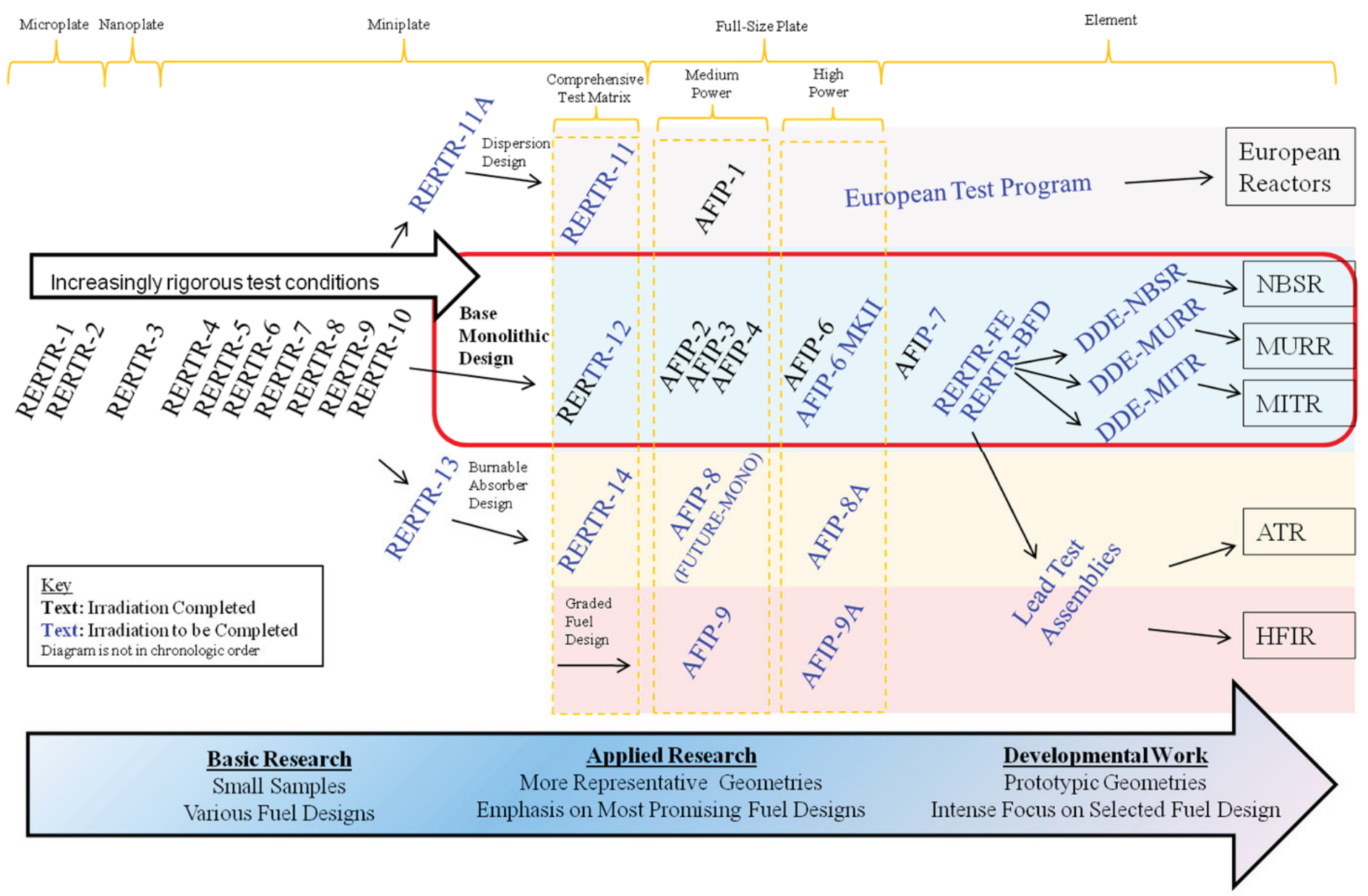

Figure 8: Progression of Irradiation Tests (current as of November 2011)

The culminating irradiation campaign for the Base Monolithic Design is the DDE campaign. More importantly, the DDE campaign represents a Development Work activity with significant maturity in terms of the technology life cycle. Due to regulatory restrictions, the DDE irradiations are not planned to be irradiated within their respective reactors as lead test assemblies. In lieu of the lead test assembly methodology, the DDE irradiations will be performed elsewhere using prototypic fuel plate geometries under prototypic conditions. Absolute prototypic conditions may not be achievable in any reactor except the one for which the LEU element is designed. However, the DDE irradiations are intended to perform several functions. The following list constitutes the core goals for the DDE campaign: ${ }^{[1]}$

- Confirm Performance under stringent prototypic parameters (e.g. heat flux, fission density)

- Show Resistance to worrisome failure modes (e.g. fission gradients, thin-clad structural stability)

- Demonstrate Fabrication by producing the plates/elements as demonstration products ${ }^{\text {[2] }}$

- Give Confidence in the LEU fuel designs prior to conversion 


\section{Irradiation Location Options}

The conceptual design and intended reactor for each DDE must be determined before any significant progress can be made in the final experiment design. Several reactors were evaluated as candidate facilities for these tests. A comparison is found in Table 4. Only those reactors/experiment positions which are large enough to accommodate meaningful experiment geometry were considered (i.e. $\geq 3$ " major dimension).

Table 4: Advantage/Disadvantage Comparison for Candidate DDE Locations

\begin{tabular}{|c|c|c|}
\hline Reactor and position & Advantages & Disadvantages \\
\hline $\begin{array}{l}\text { ATR Medium "I" Position } \\
\text { (INL, Idaho, USA) }\end{array}$ & $\begin{array}{l}\text {-High availability } \\
\text {-High operation time per year } \\
\text {-Existing channel gap probe }\end{array}$ & $\begin{array}{l}\text {-Low neutron flux } \\
\text {-Power controlled by enrichment }\end{array}$ \\
\hline $\begin{array}{l}\text { ATR Center Flux Trap Position } \\
\text { (INL, Idaho, USA) }\end{array}$ & $\begin{array}{l}\text {-High Neutron Flux } \\
\text {-High operation time per year } \\
\text {-Existing channel gap probe }\end{array}$ & $\begin{array}{l}\text {-Loop 2A must be removed } \\
\text {-Power controlled by enrichment }\end{array}$ \\
\hline $\begin{array}{l}\text { ATR NE and/or NW Flux Trap } \\
\text { Positions } \\
\text { (INL, Idaho, USA) }\end{array}$ & $\begin{array}{l}\text {-High Neutron Flux } \\
\text {-High operation time per year } \\
\text {-Existing channel gap probe }\end{array}$ & $\begin{array}{l}\text {-In use by other customers, } \\
\text { availability very limited }\end{array}$ \\
\hline $\begin{array}{l}\text { ATR Large "I" Position } \\
\text { (INL, Idaho, USA) }\end{array}$ & $\begin{array}{l}\text {-High availability } \\
\text {-High operation time per year } \\
\text {-Existing channel gap probe }\end{array}$ & $\begin{array}{l}\text {-Very Low Neutron Flux, booster } \\
\text { fuel decrease thermal flux }\end{array}$ \\
\hline $\begin{array}{l}\text { BR2 newly designed in-core } \\
\text { position } \\
\text { (SCK-CEN, Mol Belgium) }\end{array}$ & $\begin{array}{l}\text { - "Tune-able" neutron flux } \\
\text {-Large useable geometry }\end{array}$ & $\begin{array}{l}\text {-New in-core experiment channel } \\
\text { must be engineered } \\
\text {-Less operation time per year than } \\
\text { ATR }\end{array}$ \\
\hline $\begin{array}{l}\text { HFIR Flux Trap } \\
\text { (ORNL, Tennessee, USA) }\end{array}$ & -High Neutron Flux & $\begin{array}{l}\text {-In use by other customers, } \\
\text { availability very limited } \\
\text {-Fueled tests cannot be performed in } \\
\text { primary coolant }{ }^{[23]}\end{array}$ \\
\hline $\begin{array}{l}\text { HFIR Reflector Positions } \\
\text { (ORNL, Tennessee, USA) }\end{array}$ & -Reasonable availability & $\begin{array}{l}\text {-Low neutron flux } \\
\text {-Tests cannot be performed in } \\
\text { primary coolant }\end{array}$ \\
\hline $\begin{array}{l}\text { MIR newly designed in-core } \\
\text { position } \\
\text { (Research Institute for Atomic } \\
\text { Reactors, Dimitrovgrad Russia) }\end{array}$ & -Large useable geometry & $\begin{array}{l}\text {-New in-core experiment channel } \\
\text { must be engineered } \\
\text {-International complications (e.g. } \\
\text { contracting, export control) }\end{array}$ \\
\hline $\begin{array}{l}\text { OSIRIS newly designed in-core } \\
\text { position } \\
\text { (CEA, Saclay, France) }\end{array}$ & & $\begin{array}{l}-3 \text { years required to prepare for } \\
\text { testing }{ }^{[4]}\end{array}$ \\
\hline
\end{tabular}


Of the above noted Reactors and experiment positions, only a few remain as viable options. OSIRIS requires 3 years to prepare for testing and is removed from consideration because of schedule constraints. MIR is removed from consideration because of recent experience with contracting and export control considerations. ${ }^{[4]}$ HFIR is removed from consideration as they cannot irradiate these tests in primary coolant ${ }^{[23]}$ and the only position with a meaningful neutron flux is virtually unavailable. Similarly, ATR NE and NW flux traps are virtually unavailable and the ATR large "I" position have very low neutron flux. Consequently, the remaining viable options are:

- ATR Med "I" position (low fluence adequate for DDE-MITR only)

- $\quad$ ATR Center Flux Trap (CFT)

- BR-2 in-core position

\section{DDE Recommended Irradiation Location and Preliminary Designs}

\subsection{DDE-MITR}

Sixteen med "I" positions exist in the ATR and several of these are available. Since ATR will run with considerable power "tilts" between northern and southern lobes, the MITR irradiation history (where peak powers are achieved in latter cycles) can be simulated by shuffling from low to higher power med I positions. Likely, this would see DDE-MITR in the I-20 position for the $1^{\text {st }}$ cycle, followed by irradiation in the I-10 position for subsequent cycles. This option may not be necessary to accomplish the core DDE goals, but capability exists in the ATR med "I" positions.

The low irradiation user costs, high availability, and high ATR operation time per year $(\sim 215$ days per year) associated with med "I" irradiations also make it a good candidate for DDE-MITR as it will likely require the longest irradiation time of any of the DDE's. HEU elements for MITR currently can be irradiated as many as 500 full power days before they are removed from service ${ }^{[24]}$.

Although the 18 plate MITR LEU element cannot be completely circumscribed within the useable diameter of the med "I" position ( 3.125"), four full-size fuel plates can be accommodated in this position. This can be accomplished with minimal modification of the current position (i.e. removal of standard liner can). Unlike MURR, the MITR LEU design uses only one plate type. Consequently, the desire for irradiating a full size element (i.e. 18 plates) is not critical.

Preliminary analyses show that the ATR med "I" positions can provide target coolant conditions and neutron flux to DDE-MITR adequate to reach the desired peak heat flux if the fuel meat is enriched to about $40 \%$. It has also been shown that features such as thin hafnium sheets, strategic axial placement, and rotational placement can be employed to "shape" the fission map in the DDE-MITR plates to be more prototypic. The detailed calculations to determine time needed to achieve fission density targets are forthcoming and will likely show that DDE-MITR will need to be irradiated for $\sim 7$ cycles in the ATR ( $\sim 350$ full power days). A detailed sketch with preliminary DDE-MITR geometry can be seen in Appendix A. The above noted med "I" positions can be seen in Figure 9. 


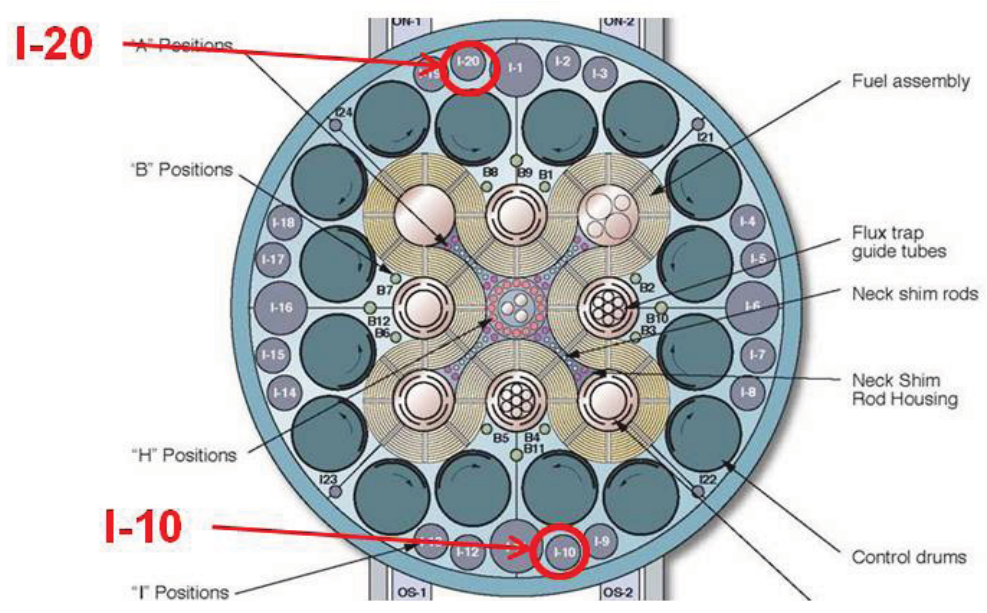

Figure 9: ATR Medium I Positions 10 and 20

\subsection{DDE-MURR}

It was found that Med "I" positions could not achieve the desired power for the DDE-MURR or DDENBSR irradiations; even with fuel enrichment of 93\%. Consequently, the DDE-MURR and DDE-NBSR irradiations were evaluated for irradiation in the ATR CFT. Due to geometric constraints, these two irradiations could not be accomplished concurrently in the CFT and were planned to be irradiated separately and sequentially. In this scenario, schedule considerations left a maximum of 3 cycles for each of the aforementioned DDE's and required the fission rates to be at least twice the intensity than prototypic conditions in order to achieve fission density goals. As a result, it was determined that either DDE-MURR or DDE-NBSR must be irradiated elsewhere; with the primary candidate being BR2. Recent experience with BR2 has shown excellent performance in quality of work, contracting, and timeliness ${ }^{[4]}$. DDE-MURR was selected over DDE-NBSR as the optimum experiment to be irradiated in BR2 for several reasons:

- Unlike the ATR CFT position, BR2 has the capability to accommodate the geometry of a full-size element. DDE-MURR is the most desirable to be a full-size element since it contains 24 distinct plate geometries (MITR and NBSR both employ an array of only one plate geometry each).

- MURR requires less fission density than NBSR. Since BR2 is operational only $\sim 120$ days per year, vs. ATR at $\sim 215$ days per year, placing DDE-MURR in the BR2 and DDE-NBSR in the ATR poses schedule benefits.

- International shipping constraints limit enrichment to $20 \%$. Since NBSR requires a fission density consistent with full LEU burn-up, the irradiation schedule of DDE-NBSR can be accelerated some if the enrichment is greater than 20 . This option is only available for domestic irradiations (i.e. ATR).

BR2 personnel performed preliminary calculations and showed that a full size DDE-MURR element could be accommodated in the core and achieve target power conditions. Detailed design work for the DDE-MURR irradiation will require issuance of a contract with BR2 in the near future. It was also noted that this path requires that channel gap probe capability be established at BR2. A detailed sketch with preliminary DDE-MURR geometry can be seen in Appendix B. The proposed experiment position for DDE-MURR in BR2 can be seen in Figure 10. 


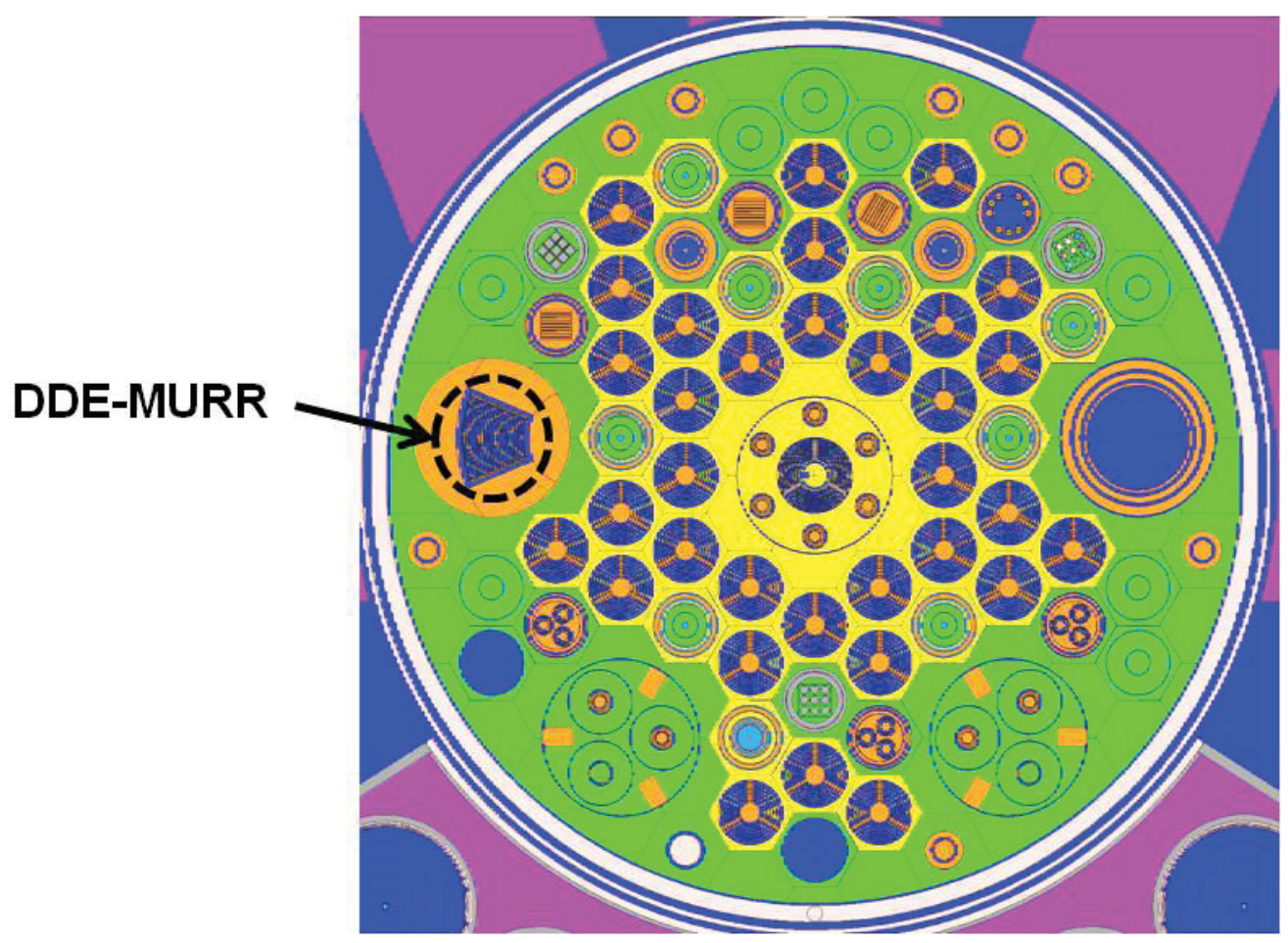

Figure 10: DDE-MURR in BR2 (Reference [25])

\subsection{DDE-NBSR}

Like DDE-MURR, the neutron flux in the Med "I" positions was found to be inadequate for meeting NBSR prototypic conditions. As described in section 4.2, the proposed irradiation of DDE-MURR in BR2 allows DDE-NBSR to be irradiated in the ATR CFT for 6 cycles. Preliminary calculations have shown this approach will meet or exceed target heat flux and fission density goals if the fuel meat is enriched to $\sim 35 \%$. This can be accomplished with nine full size NBSR plates. Flux gradient enhancers (e.g. Hf rods and water pockets) have also shown promise in amplifying the fission rate gradients within the fuel core region. This is prototypic of the conditions seen in NBSR's heavy water environment.

Removal of the Loop 2A facility will be required to utilize the full geometry of the CFT. Removal of the Loop 2A facility and impacts on competing irradiation programs are currently under evaluation by INL upper management ${ }^{[4]}$. BR2 personnel have indicated capability of irradiating two DDE experiments concurrently in separate core positions. However, irradiation of DDE-NBSR in the ATR CFT is the recommended path due to schedule considerations and is further discussed in section 4.4. A detailed sketch with preliminary DDE-NBSR geometry can be seen in Appendix C. The CFT position can be seen in Figure 11. 


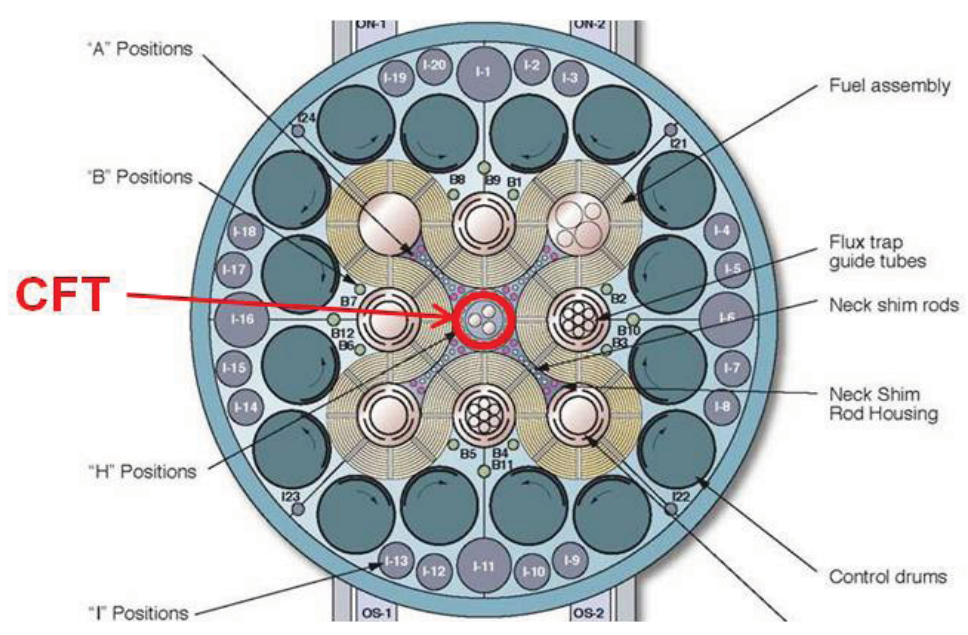

Figure 11: ATR Center Flux Trap Position

\subsection{Schedule}

Per the DDE path outlined in the previous sections, a preliminary schedule and budget were created ${ }^{[26]}$. Schedule assumptions are listed below:

- Element fabrication complete delivery dates based on reference [27].

- Conversion request dates are based on just in time delivery of the Fuel Development data.

- 49 average ATR cycle time is assumed for FY15+ cycles (the FY15+ planned cycles are not yet published).

- Core Internal Change-out (CIC) is assume 6 month length and start time per reference [28].

- Durations of BR2 based MURR activities are based on preliminary discussion with BR2 personnel and are not contracted at this time.

A Gant chart view of the preliminary schedule can be seen in Appendix D. A brief summary of the important dates contained in this schedule can be found in Table 5 .

Table 5: DDE Preliminary Schedule, Important Dates

\begin{tabular}{|c|c|c|c|}
\hline Schedule Event & MITR & MURR & NBSR \\
\hline Element Fabrication Complete & Jan 2014 & Jan 2014 & Dec 2013 \\
\hline Irradiation Commencement & Feb 2014 & Apr 2014 & Feb 2014 \\
\hline Irradiation Completion & Dec 2015 & Apr 2016 & Apr 2015 \\
\hline PIE Complete & Oct 2016 & Jun 2017 & Feb 2016 \\
\hline Conversion Request & Jul 2016 & Jul 2016 & Aug 2016 \\
\hline
\end{tabular}

DDE-MITR irradiation schedule is somewhat hampered by the ATR CIC (beryllium change-out) which is currently planned as a 6 month outage in $2^{\text {nd }}$ half of calendar year $2015^{[28]}$. This is represented in the Appendix D Gant chart as a large vertical gray bar. Similarly, BR2 is planning a beryllium change-out in approximately the same time frame $(\sim 2015)$. This is not captured on the schedule in Appendix D as the 
exact timing of BR2's beryllium change-out is still being worked out and depends on the needs of other irradiation customers. BR2 projects an outage length of one year to replace beryllium. If the BR2 beryllium change-out occurs during the DDE-MURR irradiation, then the end dates for irradiation completion and PIE completion will extend by approximately one year. This is an unmitigated schedule risk.

Since it is not the recommended path, a schedule scenario for irradiation of DDE-NBSR at BR2 has not been performed at this time. However, the following results would likely be observed:

- Fabrication delivery dates would be extended by a few months to facilitate fabrication of additional DDE-NBSR plates (it is assumed that the BR2 design of DDE-NBSR would be a full 34 plate element) [26]. This extension would not likely influence successive activities.

- Duration of test rig design and fabrication for DDE-MURR would extend by approximately six months to accommodate concurrent design of DDE-MURR and DDE-NBSR (BR2's personnel and resources for this work are somewhat limited). This would push irradiation commencement for DDE-MURR and DDE-NBSR to Oct 2014 and would extend DDE-MURR PIE completion to $\sim$ Dec of 2017 .

- The time for irradiation of DDE-NBSR would be extended significantly due to several factors:

- International shipping considerations would restrict the experiment to $20 \%$ enrichment; removing the capability to "flatten" power history via increased enrichment. Compared to the $\sim 35 \%$ enriched ATR CFT case, fission rate drop-off would become more severe as the fission density approaches that consistent with full LEU burn-up.

- NBSR requires full LEU burn-up (this is projected to take a total of 308 full power days in NBSR) ${ }^{[29]}$ and BR2 is operational $\sim 120$ days/year (vs. ATR $\sim 215$ days/year). This gives at least 2.5 years of irradiation time in BR2.

- Ultimately, irradiation of DDE-NBSR in BR2 would likely delay PIE completion well into calendar year 2018 .

It is acknowledged that none of the above scenarios show completion of DDE's in time to support conversion request dates. The schedule can be reconciled in three ways:

\section{Compression of the fabrication schedule:}

- This schedule is already very aggressive.

- Foregoing the "demonstration product" status and using bench scale fabrication techniques may accelerate the schedule some, but will fail accomplish one of the core DDE goals.

\section{Design the DDE's to irradiate in a shorter time, two options exist:}

- Boost fission rates:

o The DDE's are already designed to slightly exceed limiting conditions for each of the reactors and some are approaching the upper limit that can be delivered by the experiment position (e.g. DDE-MITR in med "I" position).

o More aggressive experiment conditions will drive each DDE further away from the prototypic envelope; increasing the risk to expose "false positive" fuel performance problems.

- Forego the ultimate fission density targets or achieve the targets in a post-conversion campaign: 
○ Unless the regulator can be convinced to "extrapolate" the high burn-up results from other campaigns (e.g. RERTR-12) to the geometries used in DDE elements, then this will likely result in a converted reactor whose regulatory basis does not allow for full utilization of fuel elements.

o Post-conversion burn-up extension programs will not be trivial.

\section{Delay the conversion schedules}

- The political ramifications of this option must be carefully considered.

\subsection{Budget}

A rough estimate cost for the DDE path outlined in the previous sections can be seen in Table 6.

\begin{tabular}{|c|c|c|c|}
\hline DDE Activity & MITR (\$K) & MURR (\$K) & NBSR (\$K) \\
\hline Design Demonstration Design \& Test Train Fabrication & $\$ 880$ & $\$ 1,240$ & $\$ 920$ \\
\hline Design Demo Characterization & $\$ 365$ & $\$ 365$ & $\$ 365$ \\
\hline Design Demo Characterization Report & $\$ 35$ & $\$ 35$ & $\$ 35$ \\
\hline Design Demo Safety Analysis & $\$ 300$ & * & $\$ 400$ \\
\hline Design Demo element shipment to BR2 & $\$-$ & $\$ 185$ & $\$-$ \\
\hline Design Demo Irradiation & $\$ 200$ & $\$ 3,920$ & $\$ 1,300$ \\
\hline Design Demo As-Run Analysis & $\$ 100$ & $*$ & $\$ 100$ \\
\hline Design Demo Cooling and Shipping & $\$ 200$ & $\$-$ & $\$ 200$ \\
\hline Design Demo PIE & $\$ 900$ & $\$ 610$ & $\$ 900$ \\
\hline Design Demo PIE Report & $\$ 50$ & $\$ 50$ & $\$ 50$ \\
\hline Develop Channel Gap Probe & NA & $\$ 265$ & NA \\
\hline Removal of CFT Loop 2A & NA & NA & $\$ 750$ \\
\hline TOTAL & $\$ 3,030$ & $\$ 6,670$ & $\$ 5,020$ \\
\hline
\end{tabular}

* MURR costs are based on BR2 estimates. MURR irradiation includes Safety Analyses and As-Runs.

\section{References}

[1] N.E. Woolstenhulme, D.M. Wachs, and M.K. Meyer, "Design and Testing of Prototypic Elements Containing Monolithic Fuel", Proceedings of the RERTR-2011 International Conference, Santiago Chile, October 23-27, 2011.

[2] D.M. Wachs, "RERTR Fuel Development and Qualification Plan", rev 5, 07/05/2011, INL external report INL/EXT-05-01017.

[3] A.B. Robinson et al., "Irradiation Performance of U-Mo Alloy Based 'Monolithic' Plate-Type Fuel - Design Selection”, INL external report INL/EXT-09-16807, Aug. 2009.

[4] M.K. Meyer and R.B. Nielsen, "Utilization of the Center Flux Trap for Irradiation During Cycles 157A - 160B”, draft white paper 11/17/11. 
[5] Lin-wen Hu, Thomas H. Newton, Jr., Erik H. Wilson, Floyd E. Dunn, and John G. Stevens, "Preliminary Safety Analysis Report Methodologies and Scenarios for LEU Fuel Conversion of the MITR Reactor", MITNRL-2011-01, April 42011.

[6] T.H. Newton et al, "Completion of the Feasibility Studies on Using LEU Fuel in the MIT Reactor", proceedings of the RERTR-2009 International Conference, Beijing China, Nov 1-5, 2009.

[7] T. Newton to N. Woolstenhulme, "RE: Conference Call DDE-MITR", email 11-21-11

[8] E. Feldman et al, "Critical Heat Flux in USHPRR Reactors - Current Status" HPRR Thermal Hydraulics Meeting June 9-10, 2010.

[9] E. Wilson to N. Woolstenhulme "RE: 2D MITR Gradients", email 10-17-2011

[10] Lin-wen Hu to N. Woolstenhulme, email "Re: MITR LEU heat flux and temperature for DDE", 9-14-11, attachment "MITR LEU fuel temps for DDE 091211.xlsx", value from 7 MW case

[11] T. Newton to N. Woolstenhulme, email "RE: DDE-MITR, heat flux", 08/23/2011.

[12] N. Woolstenhulme personal correspondence with E. Wilson, phone call 11-16-2011

[13] J.C. McKibben, K. Kutikkad, and L.P. Foyto, "Progress Made on the University of Missouri Research Reactor HEU to LEU Fuel Conversion Feasibility Study", proceedings of the RERTR-2007 International Conference, Prague, Czech Republic, Sep 23-27, 2007.

[14] J.C. McKibben to N. Woolstenhulme, "Re: Flow Velocity in MURR LEU Fuel Element", email 11-15-2011.

[15] MURR - Fuel Requirements, "University of Missouri Research Reactor", presentation given at HPRR WGM, May 2006 (For HEU Core)

[16] E. Feldman to N. Woolstenhulme, "Temperatures and Heat Fluxes for MURR LEU core", email 9-28-11, attachment "Temps_Fluxes_LEU_092711jgs.xls"

[17] A.L. Hanson and D.J. Diamond, "Calculation of Design Parameters for the HEU-to-LEU Conversion of the NBSR", October 29, 2010.

[18] TDR-0125 "Feasibility Analyses for HEU to LEU Fuel Conversion of the University of Missouri Research Reactor"

[19] S. O'Kelly to N. Woolstenhulme, "FW: Update on DDE-NBSR", email 9-22-2011.

[20] "Quality Assurance Requirements for Nuclear Facility Applications", ASME NQA-1-2008, Part IV, Subpart 4.2.

[21] "Applying Quality Assurance Requirements to Research and Development Activities", rev 3, 8/12/2010, INL Document LWP-13016.

[22] D.E. Burkes, "Overview of the GTRI Fuel Fabrication Capability (FFC) Project", presentation given at High Power Research Reactor Working Group Meeting, Cambridge Massachusetts, July 26-27, 2011.

[23] D.G. Renfro to C. Landers, "DECISION NOT TO PERFORM UNCONFINED AFIP-9 TESTS AT HFIR", email 09-21-2011.

[24] N. Woolstenhulme personal correspondence with T. Newton.

[25] E. Koonen to N. Woolstenhulme, "RE: Picture of DDE-MURR in BR2", email 11-16-11.

[26] B. Nielson to N. Woolstenhulme, "Updated DDE schedule", email 11-15-11.

[27] D.E. Burkes to N. Woolstenhulme, "RE: DDE Fab needs, best guess", email 11-16-11

[28] M.D. Love "Contract No. DE-AC07-05ID14517 - Advanced Test Reactor Core Internals Change Out Start Date Program Evaluation”, Memorandum 06/15/2011.

[29] Personal correspondence with S. O'Kelly, 8 NBSR cycles at 38.5 days each gives 308 total full power days. 
Appendix A

DDE-MITR Preliminary Design

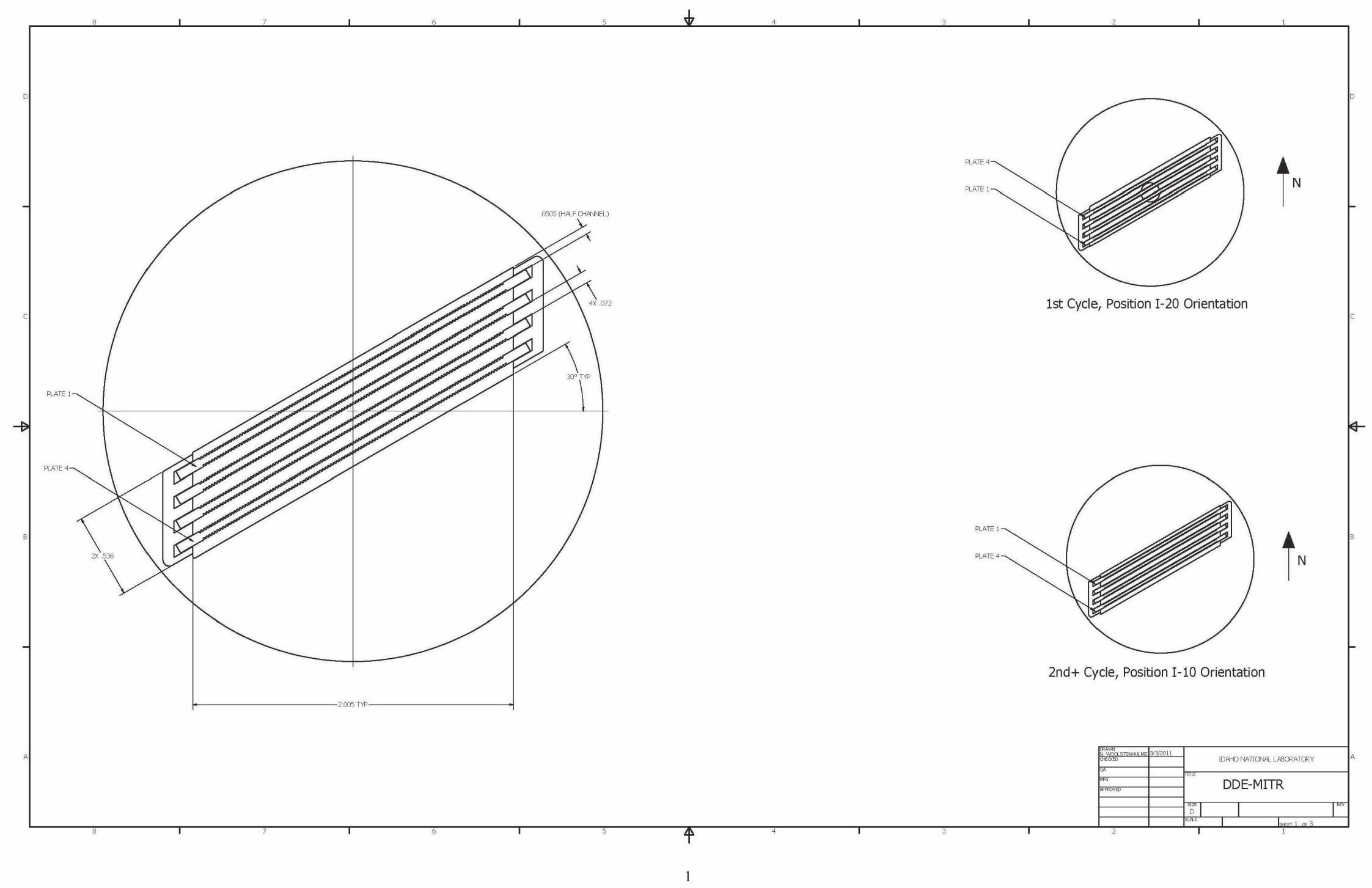


Appendix A (cont)

DDE-MITR Preliminary Design

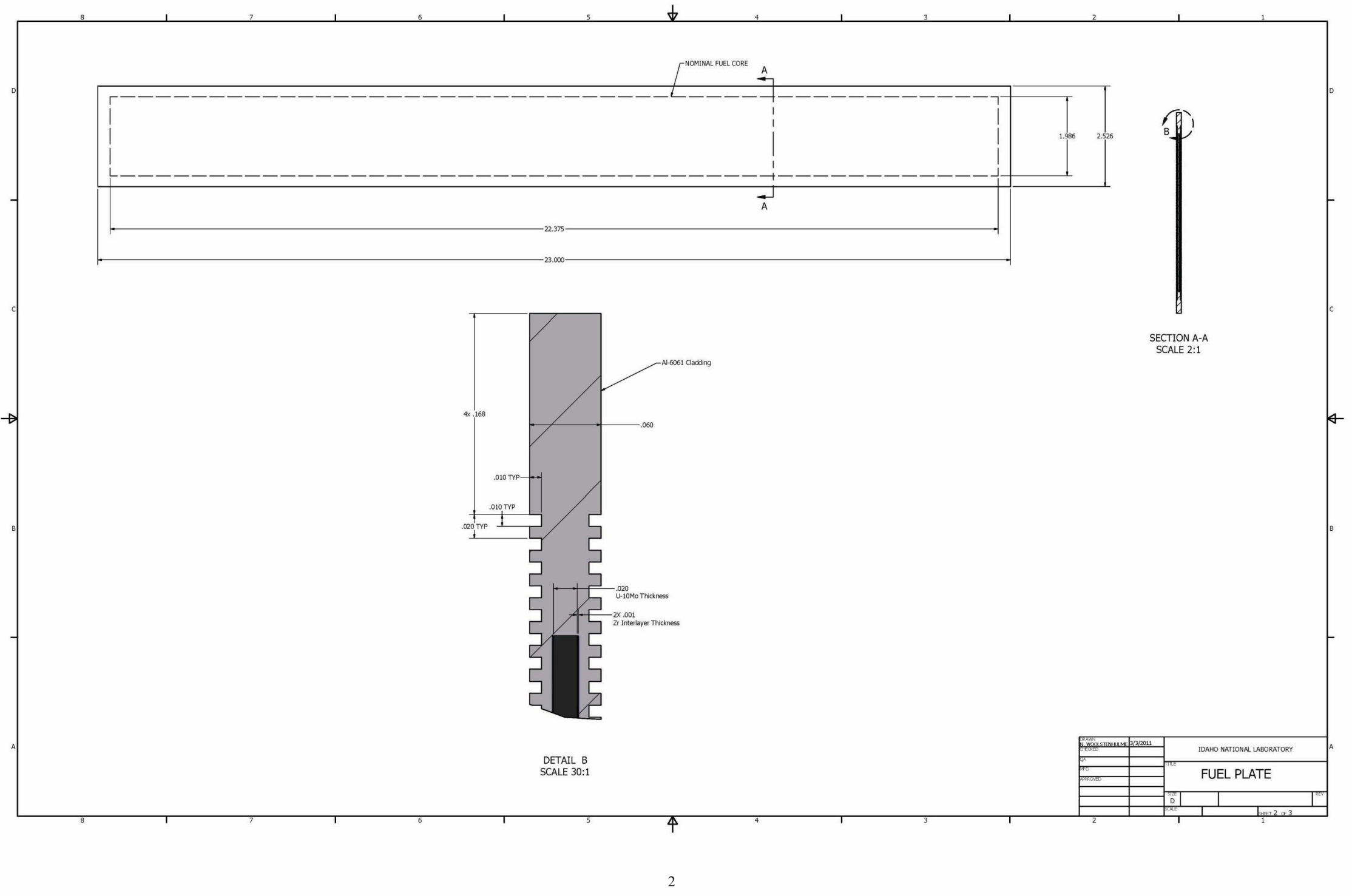




$$
\theta
$$


Appendix B

DDE-MURR Preliminary Design
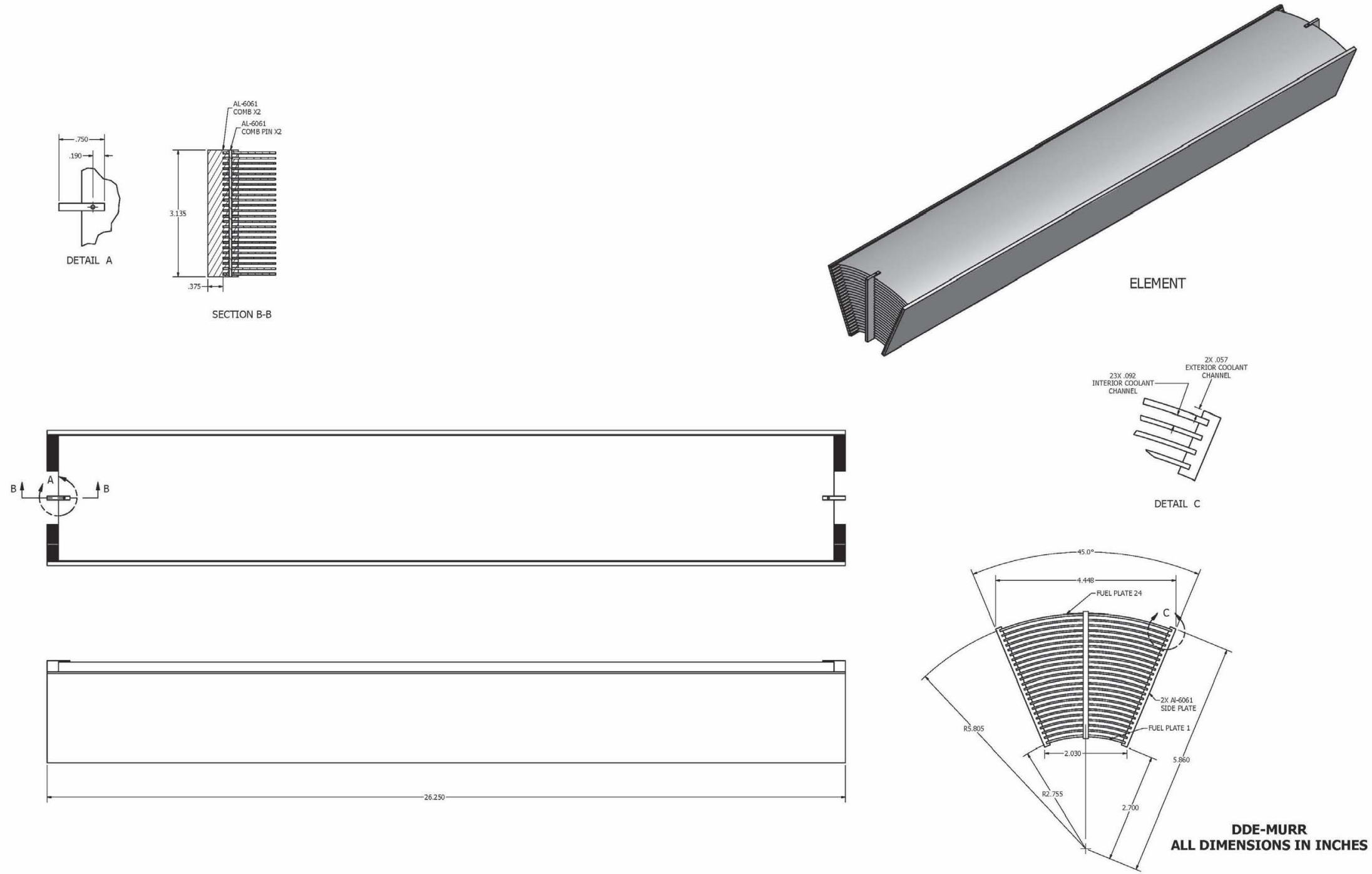
Appendix B (cont)

DDE-MURR Preliminary Design
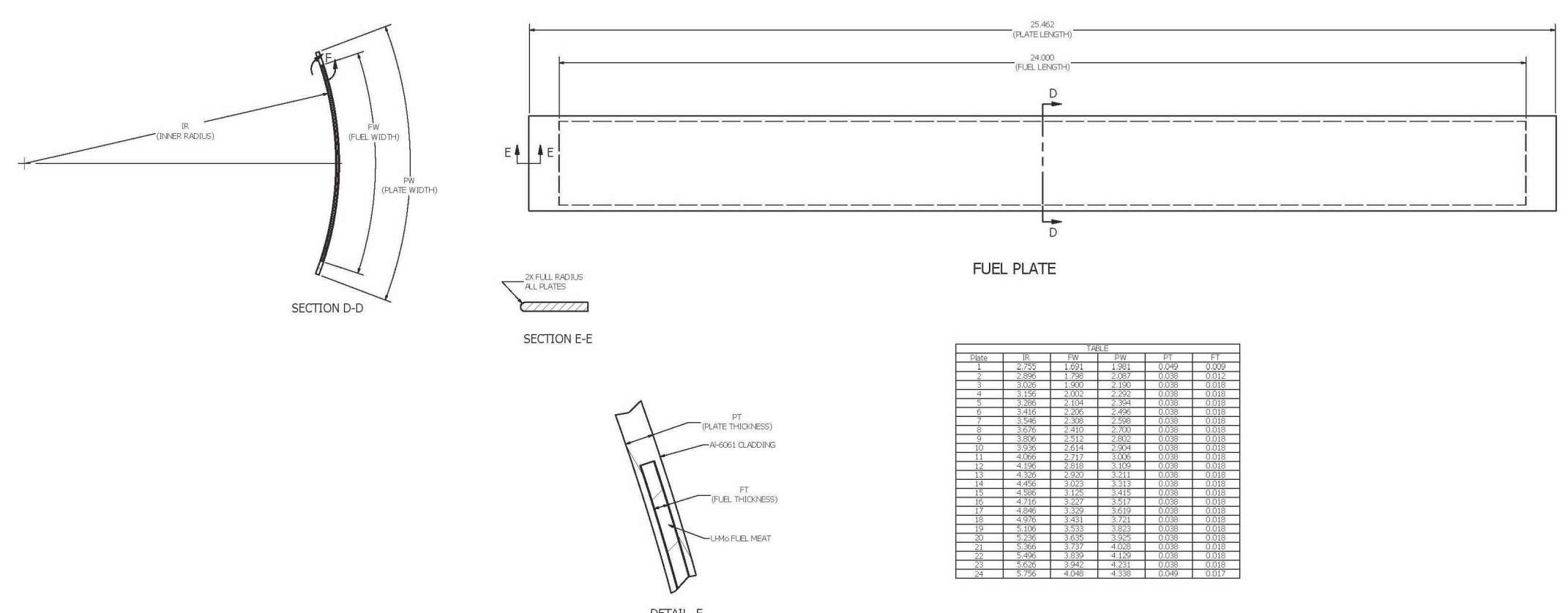

DDE-MURR ALL DIMENSIONS IN INCHES 
Appendix C

DDE-NBSR Preliminary Design

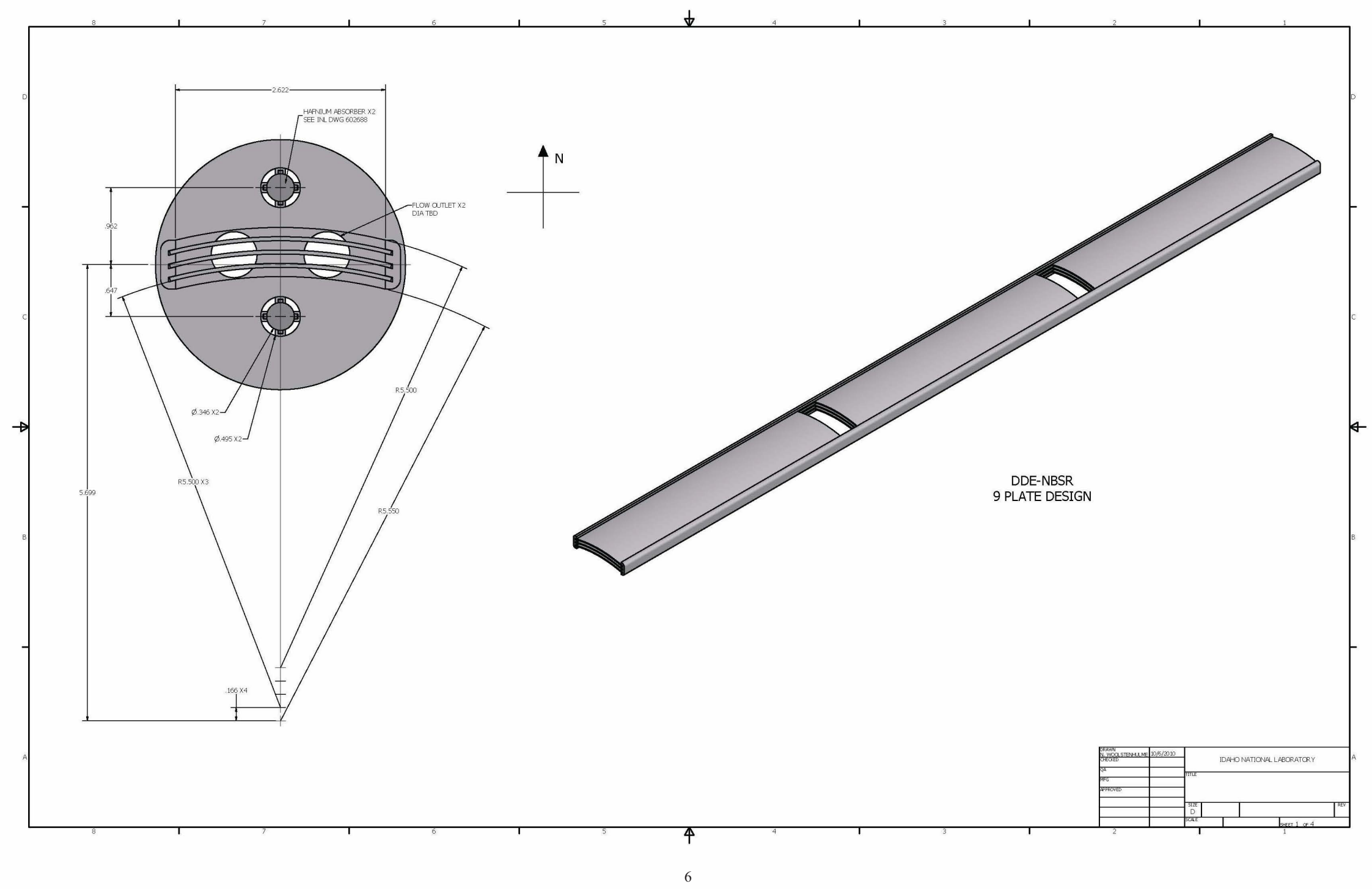


Appendix C (cont)

DDE-NBSR Preliminary Design

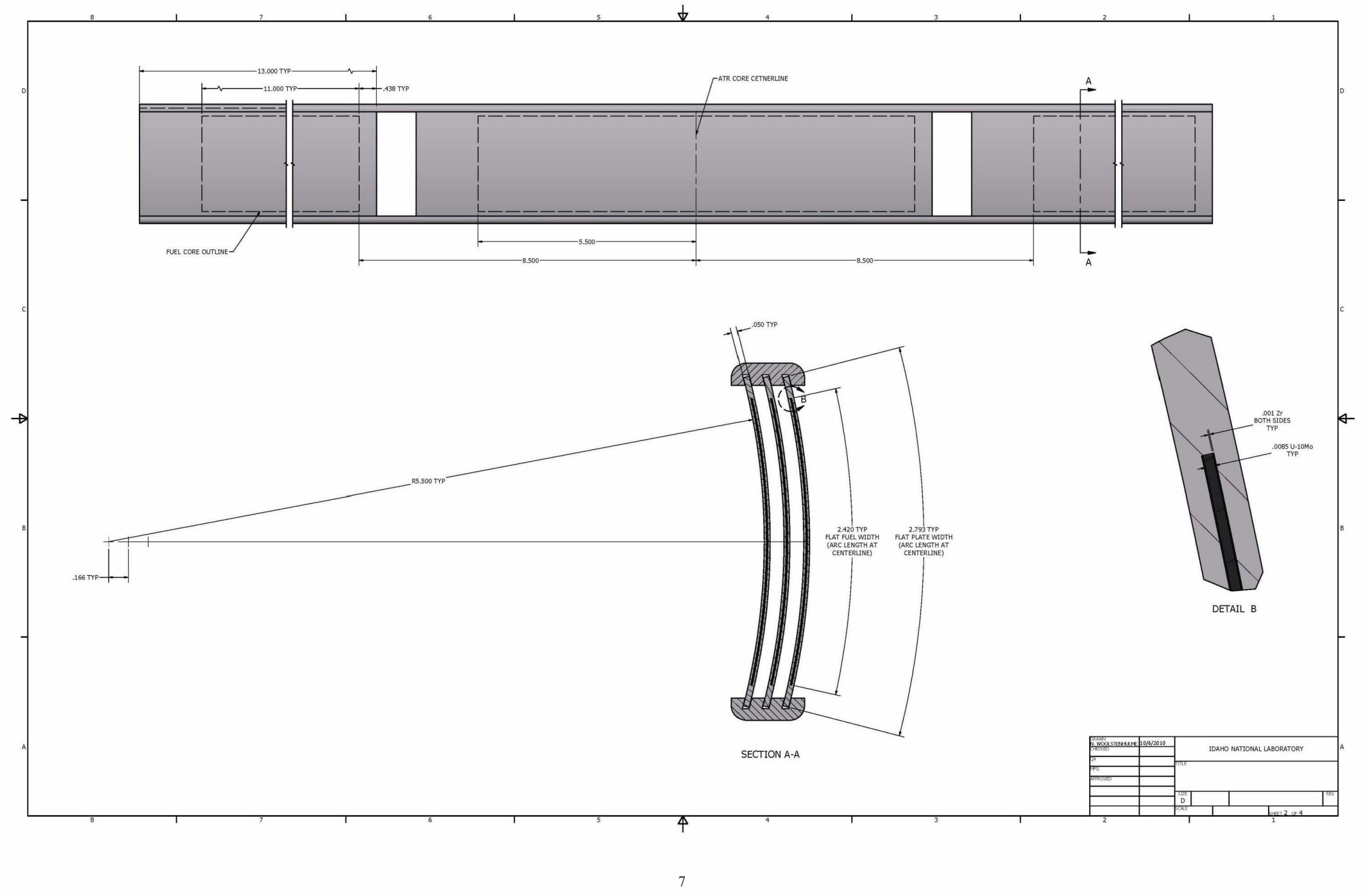


Appendix C (cont)

DDE-NBSR Preliminary Design

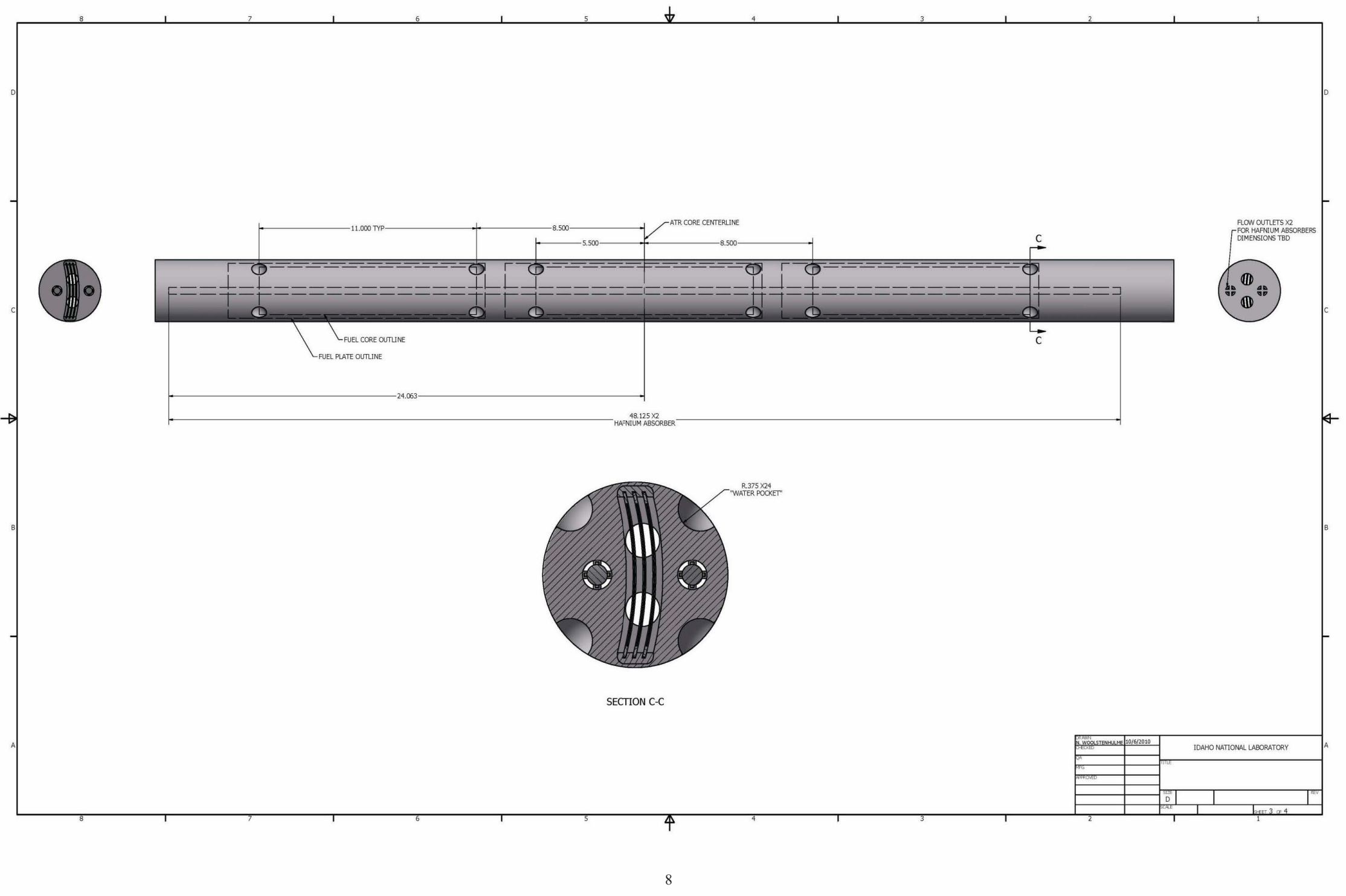


Appendix D

Preliminary Schedule

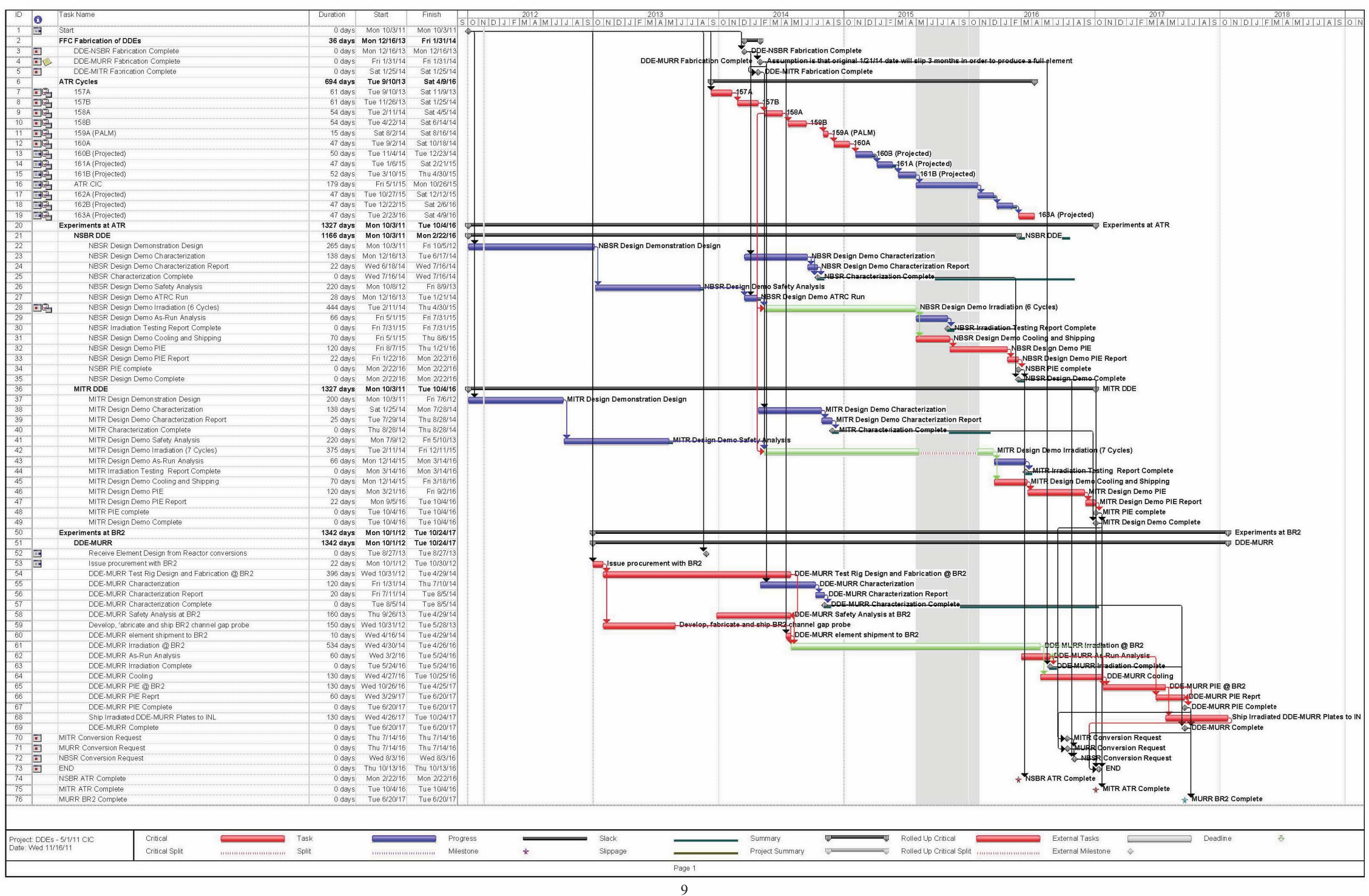

